\title{
Untersuchung von Concrementen aus thierischen Geweben.
}

Schlossberger hat Krystalle aus den Malpighischen Gefässen der Raupen und Concremente aus dem Bojanusschen Organ von Pinna nobilis untersucht, und folgende Resultate gefunden:

1) Die Krystalle in den Malpighischen Gefässen der Eichenspinnerraupe bildeten meist isolirte, glänzende, farblose Körper, die in der Regel nur eine quadratische oder oblonge Fläche erkennen liessen. Sie waren unlöslich in Wasser, Alkohol, Aether und Essigsäure, gaben keine Reaction auf Harnsäure, lösten sich in verdünnter Salz- oder Salpetersäure und verhielten sich überhaupt wie oxalsaurer Kalk.

Demnach kommt neben der Harnsäure auch die Oxalsäure als Bestandtheil sowohl des menschlichen als des Insektenharns vor.

Vielleicht sind die von Meckel in den Malpighischen Gefässen der Rrupe von Sphinx convolvuli, und die von Leydig in den Nierenkanälen von Bombyx rubi und Julus beobachteten Krystalle mit den oben beschriebenen identisch.

2) Die Concremente aus dem Bojanusschen Organ bestanden aus zwei rundlichen erbsengrossen Steinchen, von denen das eine schwarz, das andere hellbraun war, sonst beide von gleicher mikroskopischer und chemischer Beschaffenheit. Jeder Stein bestand aus einer grossen Anzahl kleiner rundlicher Körner, die unter einander nur locker verkittet waren, das Ganze einem Maulbeerstein ähnlich, mit abgerundeten Ilöckern. Daher zerbröckelten die Steine leicht zu einem Haufwerk kleiner, eiförmiger, schwarzbrauner und hellbrauner Körper, letztere concentrisch gestreift; die Streifung zeigte sich besonders deutlich nach mehrmaligem Auskochen mit Kali.

Wasser und Weingeist zogen kaum eine Spur gelben Farbestoffes aus, Aether gar nichts. Verdünnte Sänren bewirkten etwas Aufbrausen. Beim Glühen Geruch nach brennendem Horn, keine Schmelzung noch Auf blähen; der graugelbe Rückstand betrug 64,32 Proc.

Harnsäure fand sich durchaus nicht. Die Mineralbestandtheile waren phosphorsaure Kalk- und Bittererde, 1,86 Proc. $\mathrm{CaO}, \mathrm{CO}^{2}$ und eine ansehnliche Menge Eisenoxyd.

Mit starker Salzsüure zersetzten sich die Körper, 
indem sich die Säure schnell braun färbte und braune Flocken ausgeschieden wurden.

Der braune Farbstoff löste sich am besten in kochender Kalilauge mit dunkelbraunrother Farbe, wobei sich reichlich Ammoniak entwickelte, und die Körner lösten sich darauf in Salzsäure mit gelber Farbe.

Der braune Farbstoff schied sich aus der Kalilösung bei Zusatz von Salzsäure aus und war nicht ganz unlöslich in der Säure, aber fast völlig in Wasser und Weingeist und ganz unlöslich in Aether; dagegen löste er sich langsam in Ammoniak, ebenso im Vitriolöl. Durch concentrirte warme Salpetersäure wurde er schnell zerstört. Beim Erhitzen roch er stark nach brennendem Horn.

Der Verf. erkennt in diesem Farbstoff manche chemische Analogien mit dem Pigmentum nigrum des Menschen und höherer Thiere. (Ann. d. Chem. und Pharm. 98, $3 \tilde{5} 4$ flg. - Journ. f. prakt. (hem. Bd.69. Heft 3u.4.) H. B.

\section{Veber einige Salze des Harnstoffs mit organischen Săuren.}

Von den organischen Säuren sind bis jetzt nur die Oxalsäure, Cyanursäure, Lanthanursïure, Isocyanursäure, Harnsäure, Hippursäure und Milchsäure auf ihr Verbindungsvermögen mit dem Harnstoffe untersucht worden.

Von den letzten dreien hat sich die Angabe, dass sie Harnstoffsalze bilden, nicht bestätigt (Pelouze). Die erstgenannten aber stehen, wie man sich ausdriickt, noch so ziemlich auf der Grenzlinie zwischen organischen und unorgarischen Verbindungen, und sind dem Harnstoffe als Cyanverbindungen selbst nahe verwandt, so dass man sich noch fragen konnte, ob er zu den übrigen organischen Säuren dasselbe Verbindungsbestreben zeigt, oder wie weit dieses überhaupt geht. In diesem Betracht hat Hlasiwetz einige Versuche angestellt, und als er gefunden hatte, dass namentlich mit einer Anzahl krystallisirter Säuren sehr leicht eben solche Salze darstellbar sind, dachte er dieses Verhalten benutzen zu können, um das noch etwas zweifelhafte Aequivalent einiger Sïuren, die sonst nur sehr schwierig Salze geben, feststellen zu können. Die Leichtigkeit, mit der sich der Harnstoff z. B. mit der Gallussäure zu einem sehr beständigen Salze verbindet, liess ihn hoffen, solche auch mit der Catechusäure, Cetrarsäure u. a. zu erzielen: denn seine schwach- 